\title{
A tether system for psychophysiological studies in the dog
}

\author{
W. D. KEARNS, W. E. BETTER, L. A. DALEY, and D. E. ANDERSON \\ Department of Psychiatry, Johns Hopkins University School of Medicine, Baltimore, Maryland 21205
}

\begin{abstract}
A system for monitoring blood pressure or other physiological variables in the unanesthetized and chronically instrumented dog is described. An indwelling catheter attaches to a pressure transducer affixed to the underside of a leather shield, which snaps onto a custom-fitted leather vest worn by the dog. The transducer cable ascends vertically through a hollow, flexible, stainless steel tether, which is attached at the lower end to the leather shield and at the upper end to a fluid and electrical swivel. The swivel is attached to an overhead counterbalanced boom assembly, which moves in concert with the dog, maintaining a constant minimal tension on the tether. The boom assembly is attached to a wall plate via a universal joint approximately $7 \mathrm{ft}$ above floor level. Dogs can be maintained comfortably in this system $24 \mathrm{~h} /$ day over periods of months, with freedom of posture and movement, including rotational behavior. The system is economical to construct and provides versatile stimulation and recording capability and reliable long-term performance.
\end{abstract}

Blood pressure research with unanesthetized dogs continues to be facilitated by technological advances that permit observation of physiological functions over extended time intervals under increasingly naturalistic conditions. Pioneering investigations of cardiovascular conditioning in this species utilized the Pavlovian harness (Gantt, 1960), which typically involved sessions of about $1 \mathrm{~h}$ duration. Subsequently, a flexible restraint harness system that permitted increased freedom of posture and movement was developed for cardiovascular studies in behaviorally controlled dogs (Anderson, Daley, Findley, \& Brady, 1970). Recently, Barber, Quillen, and Cowley (1980) have described a system for telemetric recording of blood pressure in the free-ranging dog. This system includes a unit on the dog's back with a pressure transducer, batteries, frequency encoding, and transmitter apparatus. A remote FM receiver decodes the telemetric information for recording of blood pressure on a polygraph. The telemetric transmitter weighs a little more than $.5 \mathrm{~kg}$, and the batteries must be recharged or changed within $48 \mathrm{~h}$. Remotely controlled blood sampling is not possible with this system without disturbing the animal, and infusions of large quantities of saline would require frequent interruptions of the animal.

The present report describes a system for continuous monitoring of blood pressure of a dog connected to recording apparatus via a flexible tether and overhead boom assembly. The system permits the dog complete freedom of movement within an experimental environment (except for rolling over), due to a fluid and electronic swivel connecting the tether to the boom and the capability of the boom to move in concert with the dog. The system is relatively inexpensive and simple to construct and requires little maintenance over experimental intervals of months.

\section{CONSTRUCTION}

The system is composed of three connected components: a leather vest assembly fitted around the dog's chest, a flexible hollow steel tether, and a metal boom fitted with a fluid and electronic swivel. The assembled system is shown in Figure 1.

The leather vest assembly consists of a bottom piece with two leg holes and a top piece that has a 2.5 -in. hole in the middle for an indwelling catheter. The top piece has eight heavy-duty metal snaps around the perimeter of the hole at the sides and back. The top and bottom pieces are fitted to the dog and interlock via four articulated buckles and tongues that secure the vest anterior and posterior to the dog's forelegs (see Figure 2). The vest pieces are handcrafted to fit snugly but comfortably on the individual dog.

The tether is constructed of flexible stainless steel tubing, $5 \mathrm{ft}$ in length (Anaconda Company, Inc., Metal Hose Division). The tubing has an inner diameter of $.280 \mathrm{in}$. and an outer diameter of .365 in. A brass flange, 2.5 in. in diameter, has a .365 -in. hole drilled in the center, into which one end of the tether is soldered. The flange provides an anchor for a leather shield $(6 \times 6 \mathrm{in}$.), which attaches to the upper section of the leather vest via eight metal snaps. The center of the shield has a .365-in. hole, and the flexible tether passes through the hole until the shield rests against the flange. Holes in both the flange and shield are aligned for lacing the two together. The shield's eight mating snaps are arranged to elevate the center front area of the shield approximately $1.5 \mathrm{in}$. when attached to the vest. The elevation provides space between the shield and the vest for the attachment of electronic monitoring devices and protection of the apparatus from the dog's teeth and claws.

Cardiovascular monitoring cables and other apparatus 


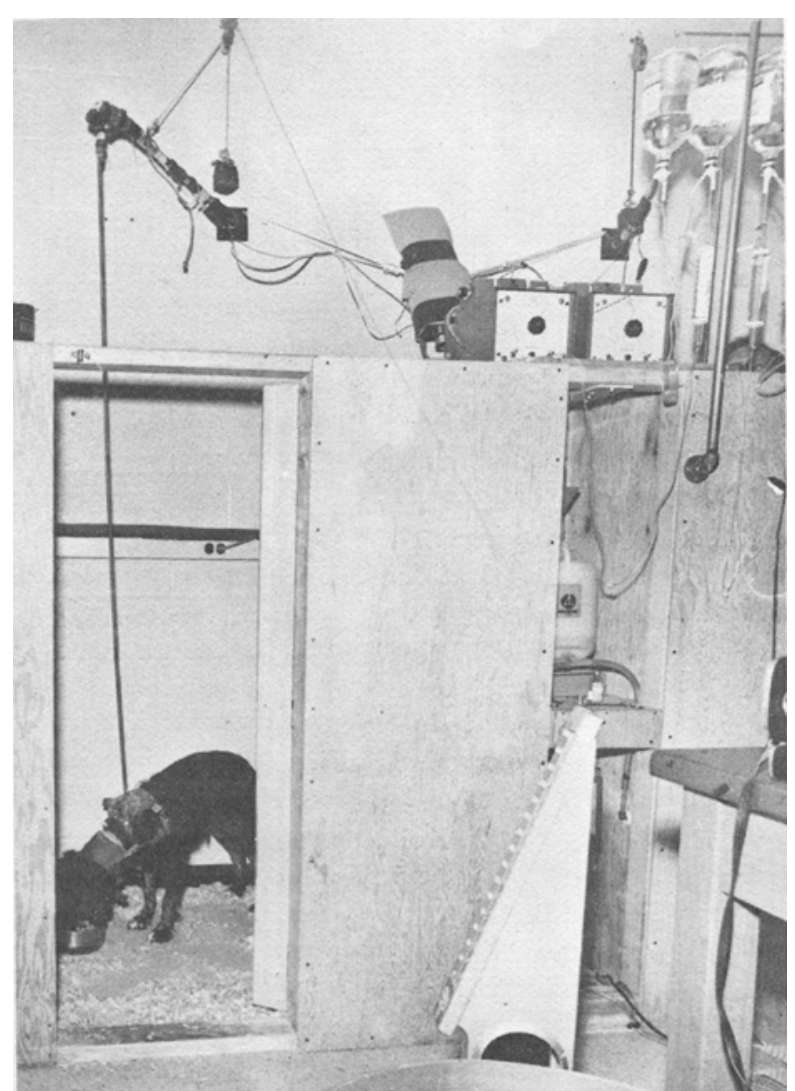

Figure 1. Photograph of a dog wearing the leather vest and connected to the tether and overhead boom assembly. The boom is approximately $7 \mathrm{ft}$ above ground level and is counterbalanced to minimize weight on the dog's back.

pass through the hollow tether and exit at its free end. An electronic connector (Cannon Model MS310A145-5S) is attached to the free end of the tether, and all soldered cables are covered with silicone glue to prevent corrosion and breakage. The three-way valve connected to the transducer is secured to the leather shield by plastic cable ties (see Figure 2). In the present application, in addition to the transducer cable (Gould-Statham Model P50), a polyvinyl catheter for infusing saline into the arterial catheter and two wires for presenting electrical stimulation are also fastened to the shield (Figure 2). The minitransducer extends 3.4 in. beyond the flange and is affixed to the center front area of the shield. The transducer's position in the pocket enables the experimenter to readily adjust the valve without detaching the tether from the vest.

The articulated metal boom (Figure 1) is made of water pipe $(.75$-in. outer diameter) threaded at both ends. To one end of the coupling is brazed the female end of a .375-in. drive universal joint (Sears Craftsman Model V4435). A .375-in. drive socket is brazed or welded to the center of a $4 \times 4 \times .25$ in. steel plate, which is anchored securely to the wall of the enclosure. The male portion of the .375 -in. drive universal joint mates easily with this mounted socket, providing for rapid detachment, as necessary. The boom is free to move horizontally or vertically as the dog changes posture or walks around, avoiding overstressing or sagging of the tether.

The other end of the boom is fitted via locknuts to a right-angle bracket made from .125 -in. mild steel (Figure 3). An electronic swivel (BRS Model CAY-960-6) is mounted vertically on the right-angle bracket via four 1.5-in.-long 4.40 screws. A ball bearing race that supports the weight of the system is made by press fitting a ball bearing (Delco Model 77038) into a $1.4 \mathrm{x}$ $1.4 \times .35$ in. thick block of aluminum. A .320 -in.-diam hole is drilled through the aluminum block so that the central core of the ball bearing is accessible to both sides of the block of aluminum. Four .156-in.-diam holes are drilled through the comers of the block, permitting the finished ball bearing assembly to be fastened later to the swivel mounting screws. A stainless steel tube measuring $1.5 \times .305$ (outer diameter) $\times .250$ in. (inner diameter) is slotted lengthwise to within .375 in. of either end. The slot's width should not exceed .625 in. One end of the tubing is then flared, and the other end is passed through the ball bearing with the aid of a vise. The wires from the swivel pass through the upper flared end of the

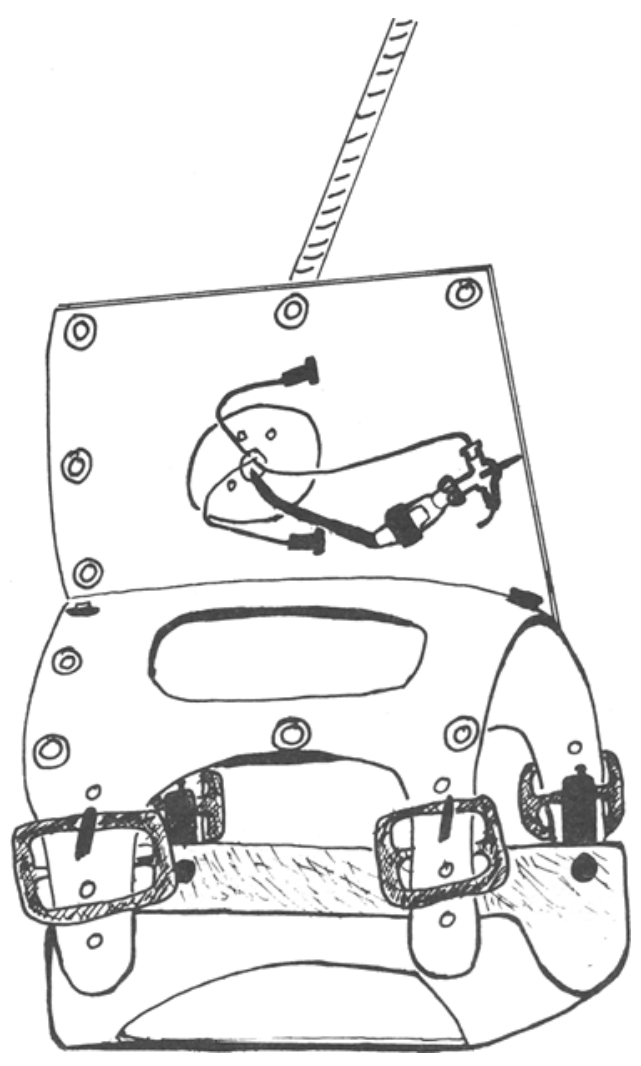

Figure 2. Photograph of the underside of the leather shield that attaches to the dog's vest. Shown are a pressure minitransducer that attaches to an indwelling arterial catheter and a saline infusion line, together with cables for presentation of stimulation. 


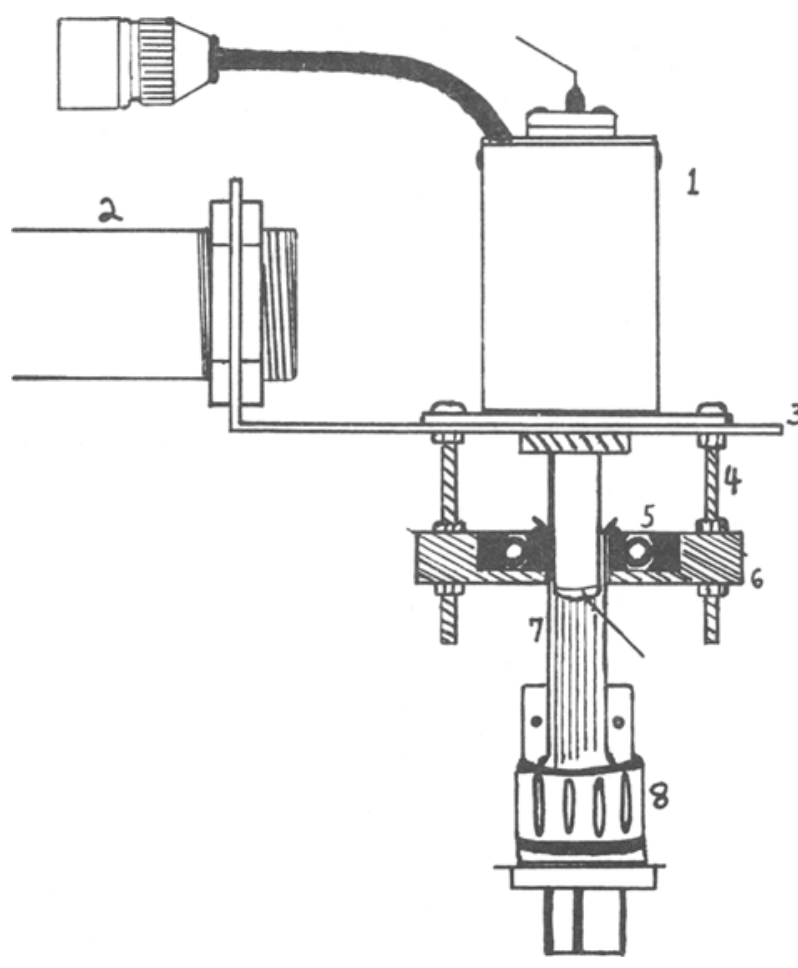

Figure 3. Cutaway diagram of the swivel assembly, illustrating construction of ball race and stainless steel support tubing. The components are (1) electronic and fluid swivel (BRS Model CAY-960-6), (2) boom assembly, (3) support plate, (4) $.125 \times 1.5$ in. screws, (5) ball bearing support race, (6) aluminum ball bearing housing, (7) stainless steel tubing, and (8) electronic connector (Cannon Model MS3101 A145-5S).

stainless steel tubing to the nonflared end, and the saline infusion line passes through the .625 -in. slot. The bearing assembly is fitted below the swivel unit (refer to Figure 3), with the swivel's central shaft centered in the steel tubing. The swivel wires exiting through the bottom of the stainless steel tubing are then fastened to the mating end of the Cannon connector (Model MS310A145-5S), and the connector is clamped to the stainless steel tube. The connector is then mated to its adjacent half in the tether, and the saline line is connected. A pulley and counterbalanced weight are secured to the wall above the boom mounting plate. The rope from the counterbalance passes through the pulley and is anchored to the boom at a point at which the entire system will be in equilibrium. Consequently, the dog feels little or no weight on its back.

Installation of the dog in the system can be accomplished in a few minutes' time. The leather vest assembly is first fitted to the dog's thoracic area, and the buckles and tongues are attached so that the vest fits snugly but comfortably. The hole in the upper piece is appropriate for indwelling catheters or monitoring devices that have been subdermally implanted. The leather shield is snapped to the upper vest via the four rearmost snaps. The four snaps on the sides of the shield are left unsnapped initially, enabling attachment of the monitoring or stimulating devices to catheters or connectors. In the present application, the arterial catheter is attached to the transducer, and the shock electrodes located on both sides of the animal's neck are attached to connectors in the backpack, after being wrapped with an ace bandage to prevent slippage. Finally, the remaining snaps are secured, and the dog is then free to move in the environmental enclosure in any direction (except rolling over).

An additional desirable feature of the system is the fact that the vest assembly can be left on the dog when the animal is removed from the tether. The cannula tubing (or monitor wires) can be wound and taped to the 2.5 -in. hole in the upper portion of the vest. A piece of leather $(6 \times 6$ in.) contoured to fit snugly over the 2.5 -in. hole is attached via eight snaps to the upper portion of the vest. This protective flap guards the delicate tubing and wiring from the animal's claws and teeth.

\section{DISCUSSION}

This system for direct and continuous monitoring of blood pressure in the tethered dog has proven suitable for observations of cardiovascular adaptations to specific behavioral conditioning procedures. The cannulated dogs are placed into the vest assembly immediately after surgery, and no adaptation period is required. Dogs have remained in the tether system continuously for periods of up to 3 months with patent arterial catheters and no equipment breakdowns. Food and water intake, general health, and body weight remain stable throughout these periods. Pharmacological agents can be infused through the system as needed for experimental purposes.

Figure 4 shows a polygraph tracing of arterial pressure, obtained from one dog in the system. The tracing illustrates the quality of the waveform displayed on the polygraph. Heart rate values are obtained by an electronic trigger and detected by an associated DEC PDP-8/e minicomputer system, which records arterial pressure every millisecond, and systolic, diastolic, and integrated

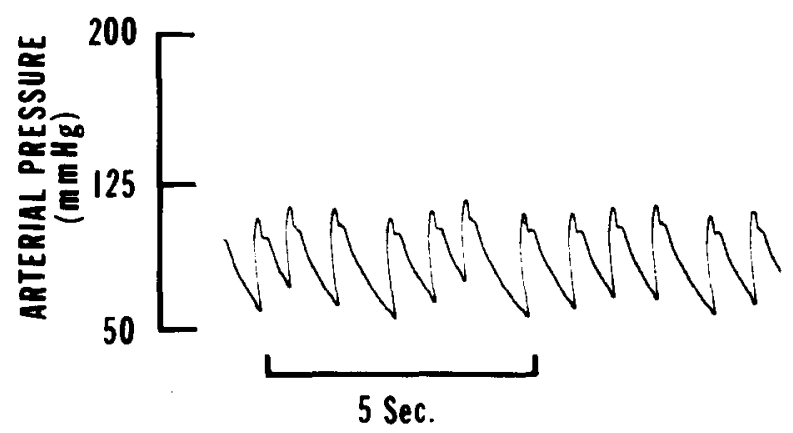

Figure 4. Polygraph tracing of arterial pressure, obtained from a dog maintained in the tether system. The cannula was implanted into the aortic arch via a carotid artery. 
Table 1

Mean Levels of Systolic (SP), Diastolic (DP), and Integrated Mean Arterial (MP) Pressure and Heart Rate (HR) Over Successive 24-h Intervals for Each of Two Tethered Dogs

\begin{tabular}{|c|c|c|c|c|c|c|c|c|}
\hline & \multicolumn{4}{|c|}{ Dog 1} & \multicolumn{4}{|c|}{ Dog 2} \\
\hline & Mean & SD & $\mathrm{CV}$ & $\mathrm{r}$ & Mean & SD & $\mathrm{CV}$ & $\mathrm{r}$ \\
\hline \multicolumn{9}{|c|}{ Day 1} \\
\hline SP & 118.2 & 3.8 & .032 & \multirow{4}{*}{.288} & 95.4 & 4.8 & .051 & \multirow{4}{*}{.391} \\
\hline DP & 76.2 & 2.8 & .037 & & 54.2 & 2.6 & .049 & \\
\hline MP & 95.7 & 3.2 & .034 & & 73.9 & 3.2 & .044 & \\
\hline HR & 97.6 & 13.2 & .136 & & 87.2 & 7.8 & .089 & \\
\hline \multicolumn{9}{|c|}{ Day 2} \\
\hline SP & 113.0 & 3.7 & .032 & \multirow{4}{*}{.282} & 99.0 & 6.3 & .063 & \\
\hline DP & 71.0 & 3.1 & .044 & & 58.5 & 3.8 & .063 & \multirow{3}{*}{.104} \\
\hline MP & 90.5 & 3.6 & .040 & & 77.9 & 4.5 & .058 & \\
\hline HR & 95.5 & 13.0 & .137 & & 76.3 & 14.8 & .194 & \\
\hline \multicolumn{9}{|c|}{ Day 3} \\
\hline SP & 107.3 & 3.4 & .032 & \multirow{4}{*}{.200} & 99.3 & 5.3 & .053 & \multirow{4}{*}{.110} \\
\hline DP & 67.2 & 1.7 & .026 & & 57.8 & 2.9 & .049 & \\
\hline MP & 86.0 & 2.5 & .029 & & 84.6 & 3.0 & .118 & \\
\hline HR & 97.7 & 9.4 & .096 & & 71.4 & 14.4 & .202 & \\
\hline \multicolumn{9}{|c|}{ Day 4} \\
\hline SP & 109.3 & 5.4 & .049 & \multirow{4}{*}{.318} & 97.0 & 5.9 & .060 & \multirow{4}{*}{.613} \\
\hline DP & 68.8 & 4.0 & .058 & & 56.7 & 2.1 & .036 & \\
\hline MP & 87.7 & 4.6 & .053 & & 76.1 & 3.9 & .052 & \\
\hline HR & 102.1 & 14.8 & .145 & & 88.0 & 7.7 & .088 & \\
\hline \multicolumn{9}{|c|}{ Day 5} \\
\hline $\mathrm{SP}$ & 107.0 & 4.0 & .038 & \multirow{4}{*}{.557} & 97.1 & 5.5 & .057 & \multirow{4}{*}{.218} \\
\hline DP & 66.0 & 2.8 & .043 & & 56.6 & 2.1 & .038 & \\
\hline MP & 84.8 & 3.0 & .036 & & 75.9 & 3.1 & .041 & \\
\hline HR & 109.3 & 13.3 & .122 & & 86.0 & 9.6 & .112 & \\
\hline \multicolumn{9}{|c|}{ Day 6} \\
\hline SP & 118.9 & 8.2 & .069 & \multirow{4}{*}{.457} & 95.6 & 4.5 & .047 & \\
\hline DP & 77.3 & 6.3 & .081 & & 55.5 & 3.1 & .055 & \multirow{3}{*}{.182} \\
\hline MP & 96.5 & 7.0 & .072 & & 74.5 & 3.0 & .041 & \\
\hline HR & 109.3 & 13.3 & .122 & & 86.0 & 9.6 & .112 & \\
\hline
\end{tabular}

Note-Data are hourly means compiled for each variable over $24 \mathrm{~h} . \mathrm{CV}=$ coefficient of variation; $r=$ Pearson product-moment correlation coefficient of mean pressure and heart rate.

mean pressure on a beat-to-beat basis. A teleprinter types out averages of each measure over successive 10 and 60-min intervals around the clock.

Table 1 presents mean levels of systolic and diastolic pressure and heart rate for each of 7 successive days in the tether system in the kennel, determined from the 24-h average values for each day. The data show that heart rate variability is consistently greater than arterial pressure variability in each dog. In addition, it was observed that changes in arterial pressure were positively correlated with changes in heart rate in each dog, as determined on the basis of hourly averages of each measure. These relationships are in accord with previous findings in studies of chronically instrumented dogs (Anderson, Yingling, \& Sagawa, 1979; Cowley, Liard, \& Guyton, 1973; Shimada \& Marsh, 1978).

In summary, three features of this system provide special advantages for long-term studies. First, components of the system can be separated rapidly, so that, in the case of electrical or mechanical malfunctions, replacement parts can be substituted with a minimum of disruption of the experiment. The system's components are constructed according to standard specifications, allowing the interchangeability of units.

Second, the counterbalancing of the boom assembly and backpack ensure that the tethered dog feels little or no weight. Consequently, the animal can move about freely in the chamber with minimal restriction. (In no instance has the leather vest and shield been damaged by the dog's behavior.)

The present application is but one of a number of potential uses of this tether system. For example, cardiac output and regional blood flows could be measured concurrently with arterial pressure by attaching the appropriate transducer cables from the dog to the electronic circuitry passing through the swivel. The system is also suitable for infusion of pharmacologic agents into the catheter, as well as for monitoring a variety of other physiological functions. The system should facilitate the acquisition of new and significant information about cardiovascular adaptations of dogs to long-term environmental and behavioral stresses. 


\section{REFERENCES}

Anderson, D. E., Daley, L. A., Findley, J. D., \& Brady, J. V. A restraint system for the psychophysiological study of dogs. Behavior Research Methods \& Instrumentation, 1970, 2, 191-194. Anderson, D. E., Yingling, J. E., \& Sagawa, K. Minute to minute covariations in cardiovascular activity of conscious dogs. American Journal of Physiology, 1979, 236, 434-439.

Barber, B. J., Quillen, E. W., \& Cowley, A. W. An inexpensive telemetry system. American Journal of Physiology, 1980, 239, 570-572.

Cowley, A. W., Liard, J. F., \& GuYton, A. C. Role of the baroreceptor reflex in daily control of arterial blood pressure and other variables in dogs. Circulation Research, 1973, 32, 564-576.

Gantr, W. H. Cardiovascular component of the conditional reflex to pain, food and other stimuli. Physiological Review, 1960, 40, 266-291.

Shimada, S. G., \& Marsh, D. J. Oscillations in mean arterial blood pressure of dogs. Federated Proceedings, 1978, 37, 233. (Abstract)

(Received for publication February 13, 1981; accepted May 25, 1981.) 